\title{
Impacts of low-speed vehicles on transportation infrastructure and safety
}

\author{
K. M. Hunter-Zaworski \\ School of Civil and Construction Engineering ${ }^{\text {a }}$ \\ Oregon State University
}

\begin{abstract}
Increasing numbers of low-speed electric vehicles (LSVs) now operate on public roadways. These vehicles are designed to be used within protected environments and on roadways with a maximum posted speed of $25 \mathrm{mph}$. Currently, these vehicles are not subject to the same federal requirements for occupant protection as passenger cars. The research reported in this paper investigated safety standards, operating regulations, and LSV manufacturer materials from sources around the world. The purpose of the research was to determine the positive and negative impacts that LSVs, including neighborhood electric vehicles (NEVs) and medium-speed electric vehicles (MSEVs), are likely to have for states such as Oregon and whether adjustments in state regulations are needed to ensure that LSVs do not negatively affect road safety and traffic operations or expose LSVs operators to undue risk. The US and Canadian federal motor vehicle safety agencies have harmonized their regulations and stipulated the maximum operating speed of these vehicles; however, state and local roadway authorities have regulated the maximum speed of roadways and intersection characteristics on which these vehicles can operate. The significant recommendations of this research are: (1) Appropriate state statues for LSVs should be amended such that LSVs are limited to public roadways with a maximum operating speed of $25 \mathrm{mph}$ and are restricted to crossing higher speed roadways at four-way stop or signal-controlled intersections; and (2) Local transportation authorities should develop parallel or secondary low-speed roadway networks that connect residential neighborhoods with major activity centers.
\end{abstract}

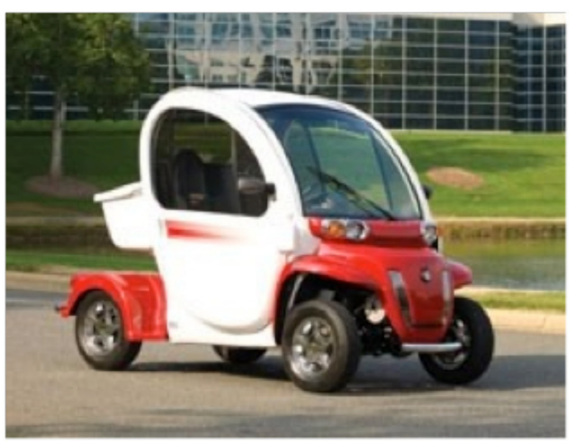

Figure 1 The GEM e2, an example of an LSV. [www.gemcar.com]

\section{$1 \quad$ Introduction}

Low-speed electric vehicles (LSVs) are becoming more common on public roadways. Although small electric vehicles have been prevalent for many years on golf courses and as mobility aids, their manufacture for use on public roadways as a shortrange alternative to fossil-fueled autos has been increasing in recent years. The US Energy Information Administration estimates that the number of electric vehicles in use nationwide has increased from 6,964 in 1999 to 53,526 in 2006-a sevenfold increase in seven years (EIA 2007). While this number is still very small relative to the overall fleet of automobiles, it is expected to increase significantly in the coming years due to increases in fossil fuel prices and new priorities for reducing dependence on fossil fuels, such as developing more sustainable transportation technologies and taking positive steps to reduce greenhouse gases.

LSVs, also referred to as neighborhood electric vehicles (NEVs), are limited to a maximum speed of $25 \mathrm{mph}$. In recent years manufacturers have introduced medium-speed electric vehicles (MSEVs), which are essentially LSVs capable of faster speeds - usually $35 \mathrm{mph}$. Both NEVs and MSEVs are expected to become more popular in the coming years for local commuting and personal errands. In this paper, NEVs that

a hunterz@engr.orst.edu

Copyright 2012 K. M. Hunter-Zaworski.

Licensed under the Creative Commons Attribution - NonCommercial License 3.0. 
are limited to a maximum speed of $25 \mathrm{mph}$ will be referred to as low-speed vehicles (LSVs), and MSEVs will refer to NEVs capable of faster speeds. It is important to note that LSVs are not in the same vehicle classification as all-electric passenger cars. The new all-electric passenger cars and trucks have met or exceeded the Federal Motor Vehicle Safety Standards for occupant protection, and these vehicles are not speed restricted or limited to low-speed roadways. Both LSVs and all-electric passenger cars and trucks have the potential to significantly reduce greenhouse gases. LSVs are already in use on many college and industrial campuses and in gated communities, such as retirement communities, in North America. These are the protected environments that LSVs were designed for. In Europe and Asia, these vehicles are increasing in number as an extended mobility and independence option for seniors and people with disabilities. Worldwide these vehicles are being driven on public roadways with posted speeds in excess of $25 \mathrm{mph}$.

LSVs, as a class of motor vehicles, differ from conventional passenger cars in significant ways. Federal Motor Vehicle Safety Standards require that LSVs be equipped with headlights, taillights, brake lights, turn signals, seat belts, and other safety features, but they are nonetheless smaller and lighter than conventional cars. A University of California study notes that such vehicles are typically shorter in length, width, and wheelbase than the American Association of State Highway and Transportation Officials (AASHTO) design for passenger cars; they also have slower acceleration (Stein, et al. 1994). LSVs are not new, but the increase in their numbers and use on public roadways has increased concerns about licensing and permitting by regulatory agencies such as state and city transportation departments. Consequently, LSVs have inherent safety risks associated with their use on public roadways and at intersections of these roadways with high-speed facilities. Thus, as LSVs continue to become more numerous on public roads, the need arises to investigate the impacts of their use to ensure the safety of the traveling public. A brief examination of US state regulations shows a range of restrictions pertaining to LSV operations. The basis of these state regulations, however, is not clear. There is a need to investigate a rational basis for regulations that would protect the public while also providing for the use of this energy-efficient, sustainable alternative to the conventional fossil-fueled passenger car for local, short-range travel.

\section{Objectives}

The specific goal of this research was to determine positive and negative impacts that LSVs, which include NEVs and MSEVs, are likely to have for the state of Oregon; however, the proj- ect results can be applied nationally. In addition, the research explored whether adjustments in current state regulations are needed to ensure that LSVs do not negatively affect road safety and traffic operations or expose LSVs operators to undue risk. International and North American operating and safety practices that support the use of these vehicles were also investigated. The research was considered timely, since LSVs have the potential to reduce greenhouse gas emissions and thus, potentially improve the quality of community life.

\section{Definitions}

For background purposes, federal, Oregon, and international definitions are presented. On June 17, 1998, the National Highway Traffic Safety Administration (NHTSA) officially included LSVs as a motor vehicle category of the Federal Motor Vehicle Safety Standards and defined LSVs in 49 CFR 571.3. According to the definition in this rulemaking, a "Low-Speed Vehicle (LSV) is a four-wheeled motor vehicle whose attainable speed in 1 mile is more than 20 miles per hour and not more than 25 miles per hour on a paved level surface and has a gross vehicle weight rating (GVWR) of less than 3000 lbs." This group includes NEVs and speed-modified golf carts with top speeds of more than $20 \mathrm{mph}$ but less than $25 \mathrm{mph}$ (NHTSA 1998).

\section{$4 \quad$ Regulations}

\subsection{Federal Motor Vehicle Safety Standards: FMVSS 500}

NHTSA has a legislative mandate- under Title 49 of the United States Code, Chapter 301, Motor Vehicle Safety-to issue Federal Motor Vehicle Safety Standards (FMVSS) and regulations, to which manufacturers of motor vehicles and equipment items must conform and certify compliance. These federal safety standards are regulations written in terms of minimum safety performance requirements for motor vehicles or motor vehicle equipment. These requirements are specified in such a manner "that the public is protected against unreasonable risk of crashes occurring as a result of the design, construction, or performance of motor vehicles and is also protected against unreasonable risk of death or injury in the event crashes do occur" (NHTSA 1998). FMVSS No.500 specifies the minimum equipment an LSVs must have to be compliant; this includes headlamps; stop lamps; turn signal lamps; tail lamps; reflex reflectors, one red on each side as far to the 
rear as practicable and one red on the rear; an exterior mirror mounted on the driver's side of the vehicle; either an exterior mirror mounted on the passenger's side of the vehicle or an interior mirror; a parking brake; a windshield that conforms to the FMVSS on glazing materials (49 CFR 571.205); a Vehicle Identification Number that conforms to the requirements of part 565 VIN; and a Type 1 or Type 2 seat belt assembly conforming to Sec. 571.209. Transport Canada has harmonized the Federal Canada Motor Vehicle Safety Standards with the US Motor Vehicle Safety Standards (Transport Canada 2008). In 2005, NHTSA amended the definition of LSVs by dropping the restriction on trucks, and instead established a 2,500-pound maximum gross vehicle weight rating (GVWR). This amendment allowed small vehicles designed for workrelated applications within the intended communities (such as landscaping or delivery) to be included within the definition of an LSV without opening the category to unintended vehicles such as street sweepers or speed-modified passenger cars. In 2006, in response to petitions for reconsideration from Dynasty Electric Car Corporation and Global Electric Motorcars (GEM) - both manufacturers of electric LSVs - NHTSA increased the maximum GVWR for LSVs to 3,000 pounds. This was done, in part, to "level the playing field" between electric and gasoline-powered LSVs by allowing for the additional weight of batteries required by electric vehicles. In addition, NHTSA limited the GVWR of an LSV to 3,000 pounds, in combination with the maximum speed limit of $25 \mathrm{mph}$, for the purpose of restricting the use of these vehicles in mixedvehicle traffic to very short trips, and to encourage their use within planned, limited environments such as retirement and gated communities (NHTSA 2008). Transport Canada, in the spirit of regulatory harmonization, also made similar amendments to its regulation and defined a low-speed vehicle as having a GVWR of less than $1,361 \mathrm{~kg}$. (Government of Canada 2008)

\subsection{Medium-speed electric vehicles}

In 1998, Environmental Motors, Porteon Electric Vehicles Inc., and Mirox Corporation petitioned NHTSA for rulemaking to create a new class of motor vehicles known as mediumspeed vehicles (MSV), which would be limited to a maximum speed of $35 \mathrm{mph}$. A number of reasons were cited in favor of this petition, the most significant of which was the potential environmental benefits, including facilitation of electric vehicle development and fuel savings. The petitioners also said this new class of vehicle would meet a set of safety standards greater than those that apply to LSVs but substantially less than the full set of safety standards that apply to other light passenger cars (NHTSA 2008). NHTSA, however, denied the petition, primarily because of safety concerns. According to NHTSA, with its $35 \mathrm{mph}$ speed limit, an MSEV would likely travel with regular urban traffic. In such a traffic environment, NHTSA requires the full set of FMVSS to prevent fatalities and serious injuries in motor vehicle collisions, which an MSEV likely would not have met (given the petitioners' proposed MSEV criteria). The presence of a roll cage or crushproof body would not guarantee that the vehicle was crashworthy and would meet the FMVSS for passenger cars (NHTSA 2008). The NHTSA action does not preclude states from registering MSEVs and regulating their operation on public roadways (IIHS 2010). Accordingly, 14 states have specified maximum allowable speeds for MSEVs.

\subsection{International experience}

New Zealand and Australia currently do not permit LVS on public roads as a result of concerns for occupant safety (Hunter-Zaworski 2010). In Europe and other parts of the world, these vehicles are defined as electric or motorized quadricycles. The European definition, which has been adopted by many nations, was developed by the European Union and is eligible for European Community Whole Vehicle Type Approval (ECWVTA). It came into effect on June 17, 1999 (UK Department of Transport 1999). Construction standards for quadricycles are harmonized at the European level, and the main instrument is the European Parliament and Council Directive "2002/24/EC — the Framework Directive." This directive requires compliance with a number of individual directives that set out requirements for particular vehicle systems. These harmonized requirements are recognized by all 27 member states of the European Community. Once the vehicle is approved to the standards of the directive by any member state, the manufacturer has access to all 27 markets (UK Department of Transport 1999).

\subsection{Summary of laws governing LSVs in the United States}

As of June 2010, Alabama, Arkansas, and Connecticut were the only states without any laws permitting low-speed electric vehicles on public roadways (Hunter-Zaworski 2010). The states that do have regulations governing LSVs may be put into one of the following categories: the maximum roadway speed limit to legally operate an LSV, and the speed limit and control of an intersection that an LSV can cross. The state regulations were classified based on the maximum roadway speed limit. Among the 50 states, approximately 35 states have specified a 
maximum roadway speed limit of $35 \mathrm{mph}$ for allowing LSVs, whereas the maximum operating speed of LSVs in those states is $25 \mathrm{mph}$. This creates a potential speed differential of $10 \mathrm{mph}$ between LSVs and other motor vehicles. There are some variations; for example, Kansas has specified the maximum roadway speed limit as $40 \mathrm{mph}$, creating a potential speed differential of $15 \mathrm{mph}$, and the states of Illinois, Maryland, and Massachusetts have specified the maximum roadway speed limit as $30 \mathrm{mph}$, resulting in a potential speed differential of $5 \mathrm{mph}$. New Jersey, West Virginia, and Rhode Island are the only states that specify a speed limit of $25 \mathrm{mph}$, which is the same as the maximum speed of LSVs (Hunter-Zaworski 2010).

State statutes also specify the maximum speed and traffic control of higher-speed roadway intersections that an LSV is permitted to cross. Thirty-six states allow LSVs to cross at the intersection of roadways having higher speed limits. This group can be further divided into two categories that include nine states that specify the type and control of the intersection, and 27 states specifying no intersection controls. Two states specifically prohibit crossing roadways with higher speed limits, and four states have no regulations concerning the speed limit of an intersection where LSVs may cross (Hunter-Zaworski 2010). Current Oregon Revised Statutes (ORS) are consistent with 40 other states, defining a low-speed vehicle as a four-wheeled motor vehicle with a top speed of more than $20 \mathrm{mph}$ but not more than $25 \mathrm{mph}$ that is permitted to operate on public roads posted at no more than $35 \mathrm{mph}$. In Oregon, a three-wheeled vehicle that is not a human-powered tricycle is defined as a motorcycle. However, there are states such as Colorado that define an LSV as a self-propelled electric vehicle that has at least three wheels in contact with the ground. The Colorado definition is more inclusive, as a three-wheeled LSV defined as a "motor cycle" can circumnavigate many regulations. Parking Enforcement vehicles in Corvallis, Oregon, are three-wheeled electric low-speed vehicles that are not subject to any LSV speed regulations because they are classified as motorcycles! Traditional motorcycles do not experience the significant speed differential that LSVs do, and many people who operate motorcycles have special license endorsements and take specific training in motorcycle safety. In Oregon, a MSEV, is defined as "an electric motor vehicle with four wheels that is equipped with a roll cage or a crushproof body design, can attain a maximum speed of 35 miles per hour on a paved, level surface, is fully enclosed, and has at least one door for entry" (ORS 2009). The presence of a roll cage or crushproof body, however, does not guarantee that the vehicle is crashworthy.

\section{$5 \quad$ Safety}

\subsection{Crash testing}

The North American regulations for LSVs currently do not require these vehicles to meet any of the crash-test requirements of conventional passenger cars, since these vehicles are designed to be used on low-speed and low-volume roadways, such as in gated communities or on educational or industrial campuses. LSVs are becoming more prevalent, however, on higher speed and more highly congested public roadways in Europe, Canada, and the United States (BBC 2007). Crash tests of LSVs have been conducted in Canada by Transport Canada, in the United States by the Insurance Institute for Highway Safety, in the United Kingdom by the Department of Transport, and in China (IIHS 2010). Videos of these tests are available in the public domain. LSVs were never designed to meet the additional crash and energy-attenuation requirements of passenger vehicles and therefore did not perform well in any of the crash tests (IIHS 2010).

NHTSA's policy that LSVs do not need to meet any crash test program in the United States, unlike other conventional passenger cars, is because the low speed and size of the vehicle, its limited operating environment, and the operator skill in combination with FMVSS No. 500 ensures appropriate safety for the occupants of these vehicles and also provides the vehicle with required crash avoidance and crash-protection characteristics (NHTSA 1998). However, given that LSV use has increased on public roadways among regular auto and truck traffic operating at higher speeds, these vehicles are becoming increasingly susceptible to risk even with the FMVSS 500 safety features and limited operating speed.

Transport Canada first conducted a series of crash tests on LSVs to determine the risks of mixing low-speed vehicles with highspeed and high-volume urban traffic. In one crash test, an LSV was subjected to a frontal crash impact test with a rigid barrier at a speed of $40 \mathrm{~km} / \mathrm{hr}(25 \mathrm{mph})$. In another crash test, a stationary LSV was subjected to a side crash test with a "Smart" microcar (Daimler AG), operating at a speed of $50 \mathrm{~km} / \mathrm{hr}$ (31 $\mathrm{mph})$. The results of both of the crash tests revealed that the impact forces resulting from the collisions were directly transmitted to the occupants of the LSVs, which would result in severe injuries or death to the passenger and driver (Transport Canada 2008) [Transport Canada Crash Test Video].

In the United States in 2009, the Insurance Institute for Highway Safety (IIHS) performed crash tests on low-speed vehicles to identify the impact of the operation of LSVs on public roadways. The IIHS was concerned about the potentially severe consequences of operating LSVs simultaneously 
with high-volume regular traffic. The Institute's chief research officer, David Zuby, said, "By allowing LSVs and mini-trucks on more and more kinds of roads, states are carving out exceptions to 40 years of auto safety regulations that save lives. It's a troubling trend that flies in the face of the work insurers, automakers, and the federal government has done to reduce crash risk" (IIHS 2010). To perform the crash test, the IIHS used two electric LSVs, both GEM e2 models produced by Global Electric Motorcars of the Chrysler Group. According to the statement of the Chrysler Group, "GEM vehicles offer customers an inexpensive, clean solution for low speed environments and comply with the National Highway Traffic Safety Administration standards for low speed vehicles which limit the maximum speed of the vehicle to 25 miles per hour" (Valdes-Dapena 2010). In the tests, the two GEM e2 LSVs were subjected to $31 \mathrm{mph}$ side crashes_one using a moving deformable barrier representing a pickup or SUV, and the other using a "Smart Fortwo" (Daimler AG) as the striking vehicle [IIHS crash test video]. The "Smart" is currently the smallest passenger vehicle on US roads that meets crashworthiness standards (IIHS 2010). The results of both side crash tests revealed that the impact of the collision on the LSV would likely cause serious or fatal injury to the LSV user. The test results also indicated that safety features such as the airbag and the side body panel on the "Smart Fortwo" conventional passenger car protected its occupant from severe injury during the crash. From the crash test results, it was concluded that LSVs with safety features such as safety belts and thermoplastic body panels (sometimes accompanied by doors) provide a substantially lower level of crash protection to their occupants during a collision than passenger cars in urban traffic (IIHS 2010). According to Zuby, "GEMs and other LSVs were not designed to protect people in a crash with a microcar like the Smart Fortwo, let alone larger cars, SUVs, and pickups in everyday traffic" (IIHS 2010). It should be noted that crash tests conducted in Europe all used very small, conventional passenger cars. No standard size or larger vehicles have been crash tested with LSVs.

\subsection{Speed differential}

The theory of minimizing speed differential on roadways is one of the basic tenets in the traditional transportation engineering discipline. A speed differential occurs when there is a vehicle moving faster or slower than the general traffic stream. One of the goals of traffic engineering is to achieve uniform traffic flow, as this increases the capacity of a roadway and improves overall safety by reducing speed fluctuations. This theory is applied to a number of situations, such as the design of offand on-ramps and the design of driveways to improve safety and access management. There are many safety issues associated with slow-speed operations. This is depicted in Solomon's Curve (Figure 2), which shows that a 10 to $20 \mathrm{mph}$ speed differential increases the collision rate (Solomon 1964; Cirillo 1968; West 1971).

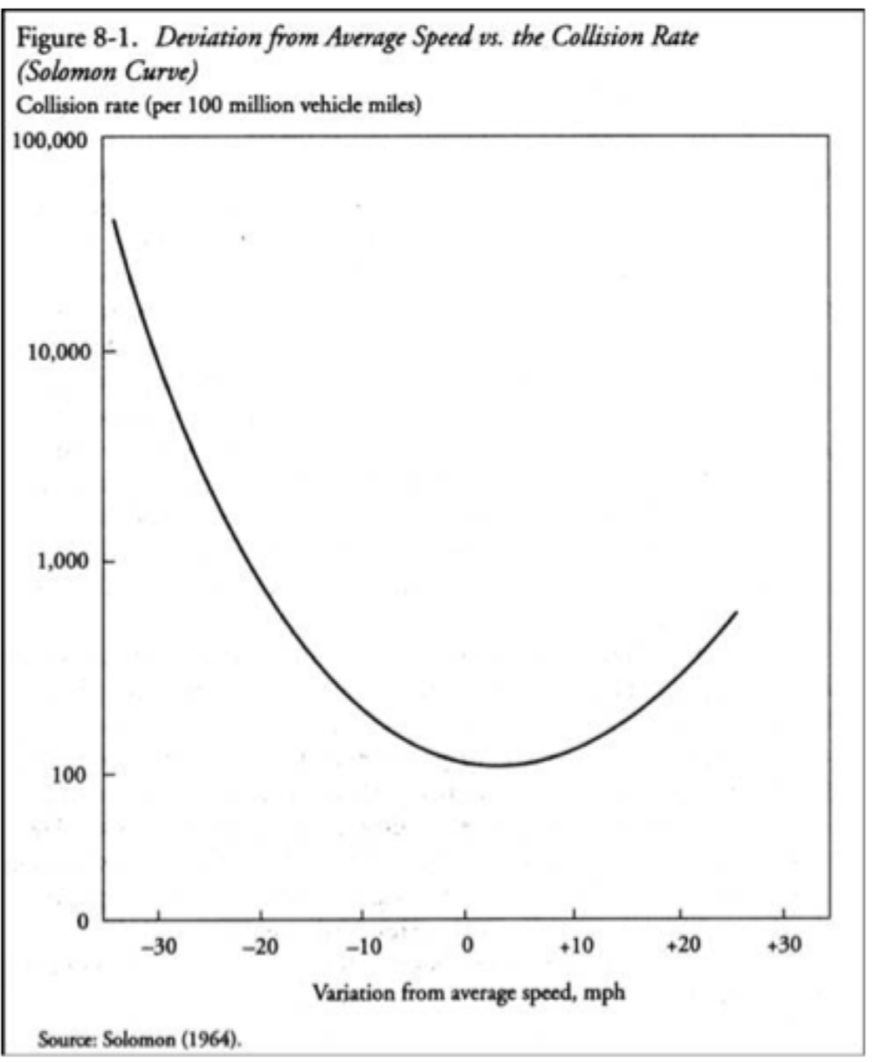

Figure 2: Solomon's curve deviation from average speed and collision rate.

Roadway regulations address only the posted speed limit, not the actual speed of the vehicles on the roadway. In general, roadway speed regulations are based on the roadway geometrics - such as number of lanes, traffic volume, and access points - and the roadway classification (collector, arterial, or highway). Other than specific truck speed regulations, roadway speeds do not consider the type, size, or weight of vehicles. It is assumed that protected low-speed environments are also low-volume roadways such as cul de sacs and neighborhood streets. There is strong evidence, however, from cities in North America and Europe, such as London, that LSVs are operating on high-volume roadways with heavy vehicles. If LSVs are limited to roadways with the maximum posted speed limit set to equal the maximum speed of the LSVs-25 mph in most regions - then the current safety regulations are appropriate, but only if the roadway does not have heavy traffic volumes or heavy vehicles. 


\subsection{Impact-resistant cabs and other safety equipment}

In 1998, when NHTSA first defined the LSV class, the primary purpose of these vehicles was to make short trips for shopping, social, and recreational purposes primarily within retirement or other planned, self-contained communities. Maintaining this goal when it redefined the GVWR-based definition of LSVs in 2003, the agency limited the GVWR to 3,000 pounds. NHTSA's rationale for this decision was that this special class of vehicles, when provided with additional amenities and characteristics of a traditional passenger car, would be driven outside the planned communities and would regularly mix with high-volume traffic on roadways, even with a $25 \mathrm{mph}$ speed limit. These special vehicles do not have any safety features such as air bags, energy-attenuating bumpers, or crash-resistant cabs. The FVMSS 500 for LSVs does not require any crash safety amenities (NHTSA 2008). None of the LSVs running on the road or available on the market today have any of these safety features. A study by Transport Canada revealed that a traditional passenger car needs to meet more than 40 safety standards, whereas LSVs are required to meet only four standards. (Transport Canada 2009)

\subsection{Vulnerability}

A study conducted in Quebec, Canada, reported that drivers of LSVs feel more vulnerable. They reported that while traveling on two-lane, two-way roadways, other drivers expressed frustration with the lack of sufficient roadway for them to overtake the slow-moving vehicle. This should not be a problem on roadways posted at $25 \mathrm{mph}$ or less; however, LSVs drivers have mentioned that other vehicle operators like to drive 5 to 10 mph over the posted speed limit (Lamy 2002).

\subsection{Energy}

LSVs are lighter than FMVSS-compliant passenger cars, and they are less crash protective than any conventional car. The forces and energy generated from a collision of an LSV with any rigid barrier or any other vehicle while operating in mainstream traffic is directly transmitted to the occupants of the LSVs. Thus, there is the potential for serious injuries or death to LSVs occupants. With an increase in speed, the kinetic energy increases proportionally with the square of the speed. For example, with a 3,000 pound GVWR, the kinetic energy generated from a collision at $35 \mathrm{mph}$ is almost twice the kinetic energy generated from a collision at $25 \mathrm{mph}$. Therefore, operating an LSV on a roadway with a posted speed limit of 35 mph and that carries high-speed traffic makes the occupants of the LSVs more vulnerable to the risk of serious injury or death. Table 1 shows the kinetic energy associated with increasing the speed of a 3,000-pound vehicle (including driver and cargo). The steep increase in the kinetic energy with increasing speeds suggests the increase of risk in an LSV collision.

Table 1: Kinetic energy associated with increasing speeds.

\begin{tabular}{cccc}
\hline $\begin{array}{c}\text { Vehicle Weight } \\
\text { (lbs) }\end{array}$ & \multicolumn{3}{c}{ Kinetic Energy (ft-lbs) at Different Speeds } \\
\hline & $25 \mathrm{mph}$ & $35 \mathrm{mph}$ & $45 \mathrm{mph}$ \\
3000 & 63,021 & 123,520 & $204,187.5$ \\
\hline
\end{tabular}

The energy generated during a collision of a conventional passenger car, which meets all the safety standards of motor vehicles in either the United States or Canada, is dissipated to a great extent before it is transmitted to the occupants inside the car. This is due to the occupant-protecting body and internal crash-protecting design attributes of the passenger car. But LSVs lack all these crash protecting attributes. So the risk of fatal injury during a collision in an LSV increases dramatically with increasing speed (Transport Canada 2008).

\subsection{LSVs insurance}

In almost every jurisdiction in the United States, each vehicle on the roadway, including low-speed vehicles, must have insurance to be qualified as "street-legal." The concept of electric LSVs is still relatively new to the US auto insurance industry, and as a result there are few insurance companies that provide coverage for LSVs - and of these, very few include any collision coverage (Johannsen 2010). Some LSVs owners in Oregon have indicated that their LSVs are insured under their homeowner's policy (Hunter-Zaworski 2010).

\section{Street Infrastructure}

Every mode of transportation has its own right-of-way, or it can share the path with other transportation modes. Passenger vehicles run on residential, collector, or arterial streets; bicycles are used on bicycle lanes, multiuse paths, or shared roadways; and pedestrians walk on sidewalks and crosswalks. There are no dedicated right-of-ways for low-speed vehicles other than in communities that are specifically designed and built to accommodate these vehicles. When LSVs share a right-of-way with higher-speed passenger vehicles and trucks, it imposes a great risk to the LSV's operator and passengers because of the speed differential and the dissimilar construction of the two types of vehicles. Also, the use of the "slow-moving vehicle" emblem 
for LSVs (like golf carts) is too limited to make faster-moving vehicles aware of and accustomed to LSVs on roadways. All these factors make the operators of LSVs more vulnerable when they run simultaneously on high-speed roadways (Stein, et al. 1996).

\subsection{Sharing the roadway}

An increased public awareness of climate change, the environment, and sustainable transportation has increased the popularity of these LSVs as a new mode of private transportation; consequently, they are becoming part of the mix of vehicles on public roadways. Some of these vehicles look like passenger cars, and many consumers are unaware of their operating and safety limitations. In the next five years, a number of all-electric passenger vehicles will come on the market that do meet the safety requirements and performance levels of passenger vehicles. It is critical in the interim that operating guidelines for LSVs are developed to protect all road users and to recognize the environmental advantages of these vehicles (HunterZaworski 2010).

\subsection{Multiuse paths}

Multiuse paths or shared-use paths are those used by pedestrians, bicyclists, equestrians, and wheeled-mobility aids operated by people with disabilities. These paths are often narrow and are not striped for two-way traffic. The rule is that all users yield to pedestrians. LSVs are much wider, heavier, and faster than pedestrians and the other devices used by people on shared-use paths; thus, there is the potential to put all the other multiuse path users at risk unless the path is designed specifically to accommodate LSVs. It is not recommended that LSVs share multiuse paths unless the paths are specifically designed for that purpose (Hunter-Zaworski 2010).

\subsection{Civic interconnectivity}

One of the challenges for LSVs operators is navigating urban roadways that meet all speed restrictions imposed on LVSs. In many communities, LSVs operators are not able to complete a trip from origin to destination without violating either speed or crossing restrictions. One solution to this problem would be for communities to identify connected secondary roadway networks that accommodate LSVs as well as other road users who operate mopeds and human-powered vehicles and who do not want to travel on high-speed, high-volume arterials. An example of this situation is in the city of Corvallis, Oregon, where one of the major north-south roadways is $9^{\text {th }}$ Street -a five-lane arterial with a center two-way left-turn lane that carries a high volume of traffic, including trucks, and connects a number of activity centers. The roadway, which has a posted $35 \mathrm{mph}$ speed limit, does include bike lanes, but many of the regular bicycle riders in Corvallis prefer to ride on $10^{\text {th }}$ Street, an adjacent residential street that runs parallel to $9^{\text {th }}$ Street. The secondary $10^{\text {th }}$ street has a marked bike lane or shared lane marking, often referred to as a sharrow; a lower speed limit of $25 \mathrm{mph}$; and lower traffic volumes generally consisting of only passenger vehicles, although the street also does connect major activity centers.

It would be prudent for state and local authorities to work with their local LSVs users and bicycle advocates to develop local networks of low-speed roadways that provide street connectivity between major residential neighborhoods and public transportation facilities and activity centers such as schools and colleges, business centers, shopping facilities, medical services, and recreational centers. The parallel secondary roadway networks should also have separate pedestrian facilities such as sidewalks. The secondary roadway network often includes minor modification of intersection control and the speed designation of certain roadways to ensure that LSVs users comply with local and state statutes (Hunter-Zaworski 2010).

\section{$7 \quad$ Conclusions}

Low-speed vehicles have become increasingly popular because of their reduced environmental impact and lower operating cost. These vehicles need to be recognized as a unique classification of vehicle with related regulations for their safe use on public roadways. The safety standards developed in Europe and North America were developed with the underlying premise that LSVs would be operated on low-speed roadways in protected environments. Therefore, the regulations do not have any provisions for occupant crash protection other than seat belts. In North America, states, provinces, and local governments have the legal authority to set regulations pertaining to motor vehicles operating on the roadways under their jurisdictions. In many circumstances, these regulations significantly increase the risk exposure to LSVs users, and the vehicle safety and roadway operating regulations are inconsistent.

\subsection{Safety parameters}

In Europe and North America, national vehicle safety organizations have worked together to harmonize the safety regulations for LSVs, in all cases with the underlying premise that these vehicles operate on protected low-speed roadways. However, 
the reality is that these vehicles are operating on public roadways with posted speed limits that, in a few states, are 10 to 20 mph above than the maximum speed of the vehicle. For the protection of all road users, there is a need to make the federal vehicle safety standards and the state and local roadway vehicle regulations consistent. If LSVs are limited to roadways with the maximum posted speed limit set to equal the maximum speed of the LSVs — and in most regions this is $25 \mathrm{mph}$ - then the current safety regulations are appropriate, but only if the roadway does not have heavy traffic volumes or heavy vehicles.

Medium-speed vehicles, which were denied a petition by NHTSA under FVMSS 500.571, should be required to meet the additional safety requirements of the FVMSS for conventional vehicles, including passing crash tests, or they should be limited to operation on roadways with a posted speed of 25 mph or lower. As stated previously, a roll cage and crushproof body is an improvement, but is not equivalent to the crash protection on a conventional passenger car.

Consumer education is needed to inform LSVs owners of the safety limitations of their vehicles. It should be noted that the lack of occupant protection in most LSVs also is reflected in the lighter weight, the increased power efficiency, and the environmental benefit of these vehicles (Hunter-Zaworski 2010). It is widely recognized by owners of certain models of LSVs that the speed governor can be modified so that the LSVs can operate at much higher speeds than $25 \mathrm{mph}$. It should be noted that this is in violation of federal and state regulations. In this situation, there is a need to either enforce existing federal and state regulations or change the occupant safety requirements for these vehicles to provide a similar level of occupant protection as that which is provided in a conventional passenger car

\subsection{Regulatory and speed harmonization}

As stated previously, the national vehicle safety organizations have worked together to harmonize safety regulations so that LSVs manufacturers only need to meet either North American or European standards for their vehicles. The challenge is that state and local authorities set the operating regulations for motor vehicles on the roadways under their jurisdictions. There is compelling evidence from the domains of roadway safety and LSV testing that LSVs should be limited to roadways with maximum posted speed limits that do not exceed the maximum operating speed of the LSVs_-generally, $25 \mathrm{mph}$.

LSVs also should be restricted to crossing higher-speed roadways at controlled intersections or intersections with stop controls on all approaches. Unfortunately, many states have regulations that permit these vehicles to travel on roadways with higher posted speed limits, which increases the vulnerability and safety risks to LSVs users. Harmonization of the local and state roadway speed regulations and federal vehicle safety regulations for LSVs would be a step toward improving safety for all roadway users.

\subsection{Operating environment}

Low-speed vehicles were developed for use in protected environments, but many people see the environmental benefit of these vehicles and are operating them on public roadways. These vehicles can be operated safely on certain public roadways such as low-speed neighborhood streets, local streets, and some collector streets with posted speed limits less than or equal to $25 \mathrm{mph}$. These roadways would provide a secondary transportation network for other types of road users who do not want to travel on higher-speed corridors.

\section{Acknowledgement}

This project was funded by the Oregon Transportation Research and Education Consortium (OTREC). The author acknowledges the support of the Oregon Department of Transportation Research Section as well as the members of the project Advisory Committee.

\section{References}

BBC News. May 23, 2007. Crash tests results of the REVA-G wiz. http://www.youtube.com/watch?v=btw3DaqJbpI

Cirillo, J.A. 1968. Interstate system accident research study II, Interim report II. Public Roads, 35 (2): 71-75.

Energy Information Administration. EIA's Annual Energy Review, Table 10.4. 2007. www.eia.doe.gov/emeu/aer/renew. html.

Government of Canada. Regulations Respecting Safety for Motor Vehicles and Motor Vehicle Components Enabling Statute: Motor Vehicle Safety Act. URL http://www.gazette.gc.ca/rppr/p2/2008/2008-08-06/html/sor-dors229-eng.html.

Hunter-Zaworski, K.M., L. Cornell, and M. Jannat. 2010. Impacts of low speed vehicles on transportation infrastructure and safety. Final report, Oregon Transportation Research and Education Consortium, Portland. Report number OTREC-RR-10-1X9.

Insurance Institute for Highway Safety (IIHS). 2010. Definitely not crashworthy. Status report, Insurance Institute for Highway Safety, Vol. 45 No. 5. URL http://www.iihs. 
org/news/rss/pr052010.html (Accessed June 2010).

Johannsen, B., 2010. Insuring an electric car. The Car Electric. URL http://www.thecarelectric.com/content/insuring-anelectric-car.php (Accessed June 2010).

Lamy, V., Assessment of low-speed electric vehicles in urban communities: Pilot project. Transportation Development Centre, Transport Canada, Report TP 13942E, April 2002.

National Highway Traffic Safety Administration (NHTSA). (1998). Notices and Final Rules: Low Speed Vehicles. 49 CFR part 571 Federal Motor Vehicle Safety Standards, Low Speed Vehicles. URL http:/www.nhtsa.gov/cars/ rules/rulings/lsv/lsv.html (Accessed June 17, 1998).

National Highway Traffic Safety Administration (NHTSA). 2008. Notices and Final Rules: Low Speed Vehicles. 49 CFR part 571 Federal Motor Vehicle Safety Standards, Low Speed Vehicles. Proposed rule.

Oregon Department of Transportation, Department of Motor Vehicles. Vehicle Code Book, Chapter 815, section 110. URL http://www.oregon.gov/ODOT/DMV/docs/vcb/ VCB815.pdf (Accessed August 17, 2010).

Oregon State Legislature. 2009. Oregon Revised Statutes. Vol. 17, Ch. 801, 803, 805, 811, and 814. URL http://www. leg.state.or.us/ors/.

Solomon, D. 1964. Accidents on main rural highways related to speed, driver, and vehicle. Washington, DC: Federal Highway Administration.

Stein, A.G., K. Kurani, and D. Sperling. 1996. Roadway infrastructure for neighborhood electric vehicles. Transportation Research Record 1444: 23-27.

Transport Canada. Question and answer for low-speed vehicles. URL http://www.tc.gc.ca/eng/roadsafety/tp-tp2436rs200803-faq-771.htm.

Transport Canada. 2008. Low-speed vehicle information sheet. Fact Sheet TP 2436E.

Transport Canada. 2009. NEV crash test, including crash test video. URL http://www.tc.gc.ca/eng/roadsafety/safevehicles-lowspeed-video-index-503.htm.

United Kingdom Department of Transport. 1999. Regulations for powered two and three-wheeled vehicles. URL http:// tna.europarchive.org/20060716091838/http://www.dft. gov.uk/stellent/groups/dft_roads/documents/page/dft_ roads_506856.hcsp (http://www.dft.gov.uk/pgr/roads/ vehicles/vssafety/regulationsforpoweredtwoandt4564 Accessed March 2010).

Valdes-Dapena, P. 2010. Ultra-light vehicles crunched in crash tests. CNNMoney.com, May 20, 2010.

West, L.B. Jr., and J.W. Dunn. 1971. Accidents, speed deviation, and speed limits. Traffic Engineering, July 1971, 5255. 